Dokuz Eylül Üniversitesi-Mühendislik Fakültesi

Fen ve Mühendislik Dergisi

Cilt 20, Sayı 60, Eylül, 2018
Dokuz Eylul University-Faculty of Engineering Journal of Science and Engineering Volume 20, Issue 60, September, 2018

DOI: $10.21205 /$ deufmd. 2018206079

\title{
Adsorpsiyon Kolon Sisteminde Pirina Kullanılarak Ağır Metal Giderimi
}

\author{
Oğuzhan GÖK¹ ${ }^{\text {Özgül ÇIMEN MESUTOĞLU² }}$
}

\author{
Aksaray Üniversitesi, Mühendislik Fakültesi, Çevre Mühendisliği Bölümü, 68100, Aksaray \\ 1(ORCID: 0000-0001-6533-9767) \\ 2(ORCID: 0000-0002-6704-8645)
}

(Alınıs / Received: 05.01.2018, Kabul / Accepted: 20.05.2018, Online Yayınlanma / Published Online: 15.09.2018)

\begin{abstract}
Anahtar Kelimeler Adsorpsiyon, Ağır metal, Akü geri dönüșüm atıksuyu, Kolon, Pirina

Özet: Zeytinyağı üretiminden atık olarak ortaya çıkan pirina ile akü geri dönüşüm tesisi atıksuyundaki ağır metallerin giderimi sabit yataklı adsorpsiyon kolonunda incelenmiştir. Çalışmada, Aksaray Organize Sanayi bölgesinde yer alan akü geri dönüşüm tesisi atıksuyu kullanılmıştır. Ağır metal giderim çalışmasında adsorpsiyona etki eden akış hızı ve kolon yatak yüksekliği incelenmiştir. Akü geri dönüşüm atıksuyunun ham $\mathrm{pH}$ ve ağır metal konsantrasyonunda; maksimum giderim verimine $30 \mathrm{~mL} / \mathrm{dk}^{\prime} \mathrm{lk}$ bir akıș hızı ve $25 \mathrm{~cm}$ 'lik bir kolon yüksekliğinde ulașılmıștır. Akü geri dönüşüm atıksuyundaki $\mathrm{Pb}(\mathrm{II}), \mathrm{Zn}(\mathrm{II}), \mathrm{Ni}(\mathrm{II})$ ve $\mathrm{Cu}(\mathrm{II})$ için ortalama $\% 98$ 'lik giderim verimi sağlanmış olup, ağır metal adsorplanma kapasitesi $2.64 \mathrm{mg} / \mathrm{g}$ olarak hesaplanmıştır. Elde edilen sonuçlar doğrultusunda, aktifleştirilmiş pirinanın kullanımıyla akü geri dönüșüm atıksuyundaki ağır metallerin uzaklaștırılması ekonomik bir çözüm yolu sunmaktadır.
\end{abstract}

\section{Heavy Metal Removal by using Olive Pomace in Adsorption Column System}

Keywords
Adsorption,
Battery recycling
wastewater,
Column,
Heavy metal,
Olive pomace

Keywords

Adsorption Battery recycling (astewater, Olive pomace 
(II). In the direction of the results obtained, heavy metal removal using activated olive pomace offers an effective method for the economic treatment of battery recycling wastewater.

*Sorumlu yazar: ozgulcimen@gmail.com

\section{Giriş}

Günümüzde hızla artan nüfus ve sanayileşme faaliyetleri sebebiyle çevre ortamlarında ağır metal kirliliği sorun teşkil etmektedir. Ağır metal kirliliği (kurşun, çinko, nikel, kadmiyum, bakır vb.), insan ve sucul ortamlardaki canlılara toksik ve kanserojen etkilere sahiptir ve bu sebepten dolayı alıcı ortamlara deşarj edilmeden önce giderilmesi gereken kirleticiler arasında yer almaktadır [1-3].

$\mathrm{Bu}$ tehlikeli kirleticiler endüstriyel, tarımsal, atıkların yok edilmesi ve askeri faaliyetler sonucunda oluşmaktadır. Endüstriyel atıksular ağır metal kirliliğinin en bașta gelen kaynağıdır. Ağır metal gideriminde pek çok metot kullanılmaktadır. Ağır metal gideriminde kullanılan en yaygın yöntemler arasında koagülasyon, filtrasyon, ters ozmos, iyon değişimi ve adsorpsiyon prosesleri yer almaktadır [4-6].

Adsorpsiyon prosesi diğer arıtma yöntemlerine kıyasla düşük maliyetli, basit, yüksek verimlilik ve kullanım kolaylığı nedeniyle büyük ilgi görmektedir [7,8].

Adsorpsiyon sisteminde adsorban olarak aktif karbonun kullanımı oldukça yaygındır. Ancak ticari bir malzeme olan aktif karbon maliyetli olduğundan, son yıllarda düşük maliyetli olan doğal adsorbanlar ile adsorpsiyon çalışmaları yapılmaktadır $[9,10]$. $\mathrm{Bu}$ çalışmalar sonucunda endüstriyel ve evsel atıkların değerlendirilmesiyle ülke ekonomilerine ve çevreye olumlu katkı sağlanmaktadır. Yapılan çalışmalarda kullanılan düşük maliyetli doğal atıklardan elde edilen adsorbanların adsorpsiyon kapasitelerini artırmak için modifikasyon işlemleri uygulanmaktadır. Fiziksel ve kimyasal modifikasyonlar tek tek yapılabildiği gibi beraber de kullanılabilmektedir [11,12]

$\mathrm{Bu}$ modifikasyonlar arasında en yaygın olanları asit ve solventler gibi kimyasallarla muamele ile yüksek sıcaklıklarda oksijensiz ortamlarda termal işlemdir [13].

Farklı organik ve inorganik adsorbanlar kullanılarak yapılan ağır metal giderim çalışmalarına literatürde rastlanmaktadır. Bunlardan bazıları findık kabuğu [14], pirinç kabuğu [15], kaolin [16], bentonit kili [17], muz kabuğu [18], findık ve badem kabuğu [19], fistık kabuğu [20] dur.

$\mathrm{Bu}$ çalışmada; zeytin posasının aktifleștirilmesiyle elde edilen aktifleştirilmiş pirina ile akü geri dönüşüm tesisi atıksuyundaki ağır metallerin giderimi üzerine; akış hızı ve kolon yüksekliği parametrelerinin etkisi sabit yataklı bir adsorpsiyon sisteminde incelenmiștir. Tarımsal faaliyetlerden elde edilen düşük maliyetli adsorban kullanımı ile ağır metal içeren gerçek atıksu çalışmasının literatüre katkı sağlaması amaçlanmıştır.

\section{Materyal ve Metot 2.1. Materyal}

Deneysel çalışmada adsorban olarak kullanılan pirina, Marmara Bölgesi'nde zeytinyağı üretimi yapan bir fabrikadan temin edilmiştir. Pirina, zeytinyağ üretiminde zeytinden yağ çıkartılması sırasında elde edilen çekirdek ve etlikabuklu kısımdan oluşan; \%10-35 nem, \%6-15 yă̆, \%7-13 protein, \%32-42 karbonhidrat, \%27-42 selüloz ve \%3-8 kül içeren katı atıktır [21]. Ham pirinanın (HP) fizikokimyasal özellikleri Tablo 1'de verilmiştir. HP, birkaç kez deiyonize su ile ylkandıktan sonra etüvde 24 saat $105^{\circ} \mathrm{C}$ 'de kurutulmuştur. HP'nin aktif yüzeylerinin artırılması için aktifleştirme 
işlemine tabii tutulmuştur. $\mathrm{Bu}$ işlem oksijensiz ortamda $300^{\circ} \mathrm{C}^{\prime}$ deki etüvde 1,5 saat azot gazı verilerek yapılmıştır ve aktifleștirilmiş pirina (AP) elde edilmiştir $[22,23]$. Aktifleştirme işlemi sonucunda HP'nin sahip olduğu gözenek yapısı artırılarak kirleticinin tutunacağı yüzey alanı artırılmıștır. HP ve AP'nin görüntüsü ise Şekil 1'de görülmektedir. Ayrıca bu çalışmada giderimi amaçlanan akü geri dönüşüm tesisi atıksuyunun ağır metal içeriği Tablo 2'de görülmektedir. Kullanılan atıksuyun pH'ı 1.8-2.2; askıda katı madde konsantrasyonu ise 270-340 $\mathrm{mg} / \mathrm{L}$ aralığında değişmektedir. Atıksu, adsorpsiyon kolonuna verilmeden önce içerisindeki askıda katı madde konsantrasyonunun ağır metal giderim verimine etki etmemesi için birkaç kez cam yününden geçirilmiştir.

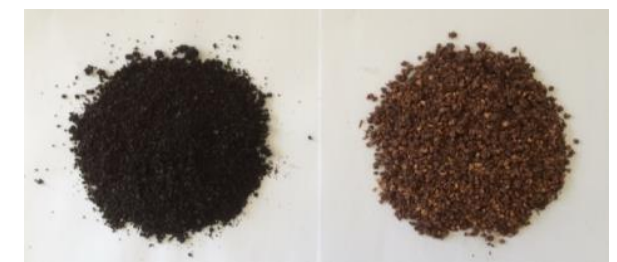

Şekil 1. Calıșmada kullanılan HP ve AP görüntüsü

Tablo 1. HP'nin fizikokimyasal özellikleri [24].

\begin{tabular}{cc}
\hline Element & Miktar (\%) \\
\hline Karbon $(\mathrm{C})$ & 53.23 \\
Oksijen $\left(\mathrm{O}_{2}\right)$ & 37.39 \\
Hidrojen $(\mathrm{H})$ & 7.132 \\
Azot $(\mathrm{N})$ & 2.249 \\
\hline
\end{tabular}

Tablo 2. Akü geri dönüşüm tesisi atıksuyu ağır metal içeriği.

\begin{tabular}{cc}
\hline Ağır metal & Miktar (mg/L) \\
\hline $\mathrm{Pb}(\mathrm{II})$ & $5.3 \pm 0.5$ \\
$\mathrm{Zn}(\mathrm{II})$ & $44.7 \pm 1.8$ \\
$\mathrm{Ni}(\mathrm{II})$ & $2.7 \pm 0.3$ \\
$\mathrm{Cu}(\mathrm{II})$ & $1.8 \pm 0.2$ \\
\hline
\end{tabular}

\subsection{Metot}

Adsorpsiyon kolonunun kapasitesini belirlemek için kolon kırılma eğrilerinin atıksu hacmine ve zamana karşılık çizilen grafiklerinin görünümü ve şekli önemli faktörlerdendir [25]. Kolon kırılma noktası kolondan dıșarı çıkan çözelti konsantrasyonunun $\left(\mathrm{C}_{\mathrm{e}}\right)$ kolona girișteki çözelti konsantrasyonuna $\left(\mathrm{C}_{0}\right)$ oranının yaklaşık \%5-10 olduğu noktadır. Bu oranın \%95'e ulaşması ile de kolonda bulunan adsorbanın yenisi ile değiştirilmesi gerekmektedir. Laboratuvar ortamındaki kolon çalışmalarındaki ana amaç, gerçek ölçekli adsorpsiyon sistemlerine geçilmeden önce adsorpsiyon yatağının kapasitesini tahmin edebilmektir [26].

Gerçek atıksu ile yapılan adsorpsiyon kolonu çalışmalarında özellikle akış hızı ve yatak yüksekliği değişkenlerin adsorpsiyon prosesini nasıl etkilediği araştırılmaktadır [27].

Ağır metal analizleri, ICP-OES (Perkin Elmer Optical Emission Spectrometer Optima 2100 DV) cihazı ile SM 3120B'ye göre gerçekleştirilmiştir.

Akü geri dönüşüm tesisi atıksuyu için kolon kırılma noktasındaki adsorplanan metal miktarı (qu; mg/g) Eşitlik (1)'den hesaplanır:

$$
\mathrm{q}_{\mathrm{B}}=Q_{V}\left(C_{0}-\frac{C_{B}}{2}\right) \frac{t_{B}}{m_{\text {adsorban }}}
$$

$\mathrm{C}_{0}$ kolona giren kirletici konsantrasyonu (mg/L), madsorban kolon içerisindeki adsorban miktarı (g), $Q_{\mathrm{v}}$ akış hızı (mL/dk), С в kırılma noktasındaki metal iyon konsantrasyonu (mg/L) ve tв kırılma noktası zamanı (dk) dır.

Akü geri dönüşüm tesisi atıksuyunda metal arıtımı için kullanılan adsorpsiyon kolon sistemi Şekil 2'de verilmiştir. 


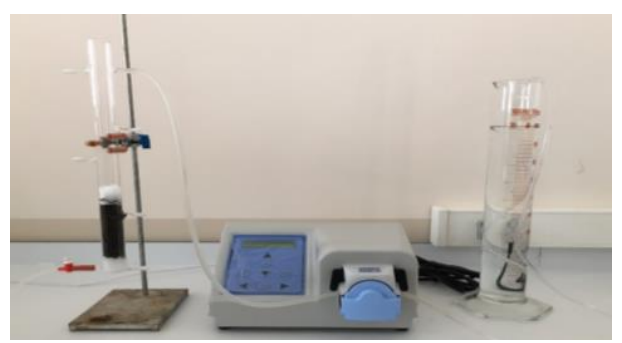

Şekil 2. Deneysel çalışmada kullanılan adsorpsiyon kolon sistemi

\section{Bulgular}

\subsection{Kolon yatak yüksekliğinin etkisi}

AP ile yapilan adsorpsiyon kolon çalışmasında kolon yüksekliğinin etkisi incelenirken; akü geri dönüşüm tesisi atıksuyu 15 ve $25 \mathrm{~cm}$ kolon yüksekliğine karşıllık gelen; 45 ve $75 \mathrm{~g}$ adsorban ile doldurulmuștur. Kolon kırılma eğrisini gösteren grafikler sırasıyla Șekil 3 ve Șekil 4 'te verilmiştir. AP yatak yüksekliğinin adsorpsiyon kolon kırılma eğrisine etkisi incelenirken; 15 ve $25 \mathrm{~cm}$ yatak yüksekliklerinde $20 \mathrm{~mL} / \mathrm{dk}$ akış hızında çalışılmıştır. $25 \mathrm{~cm}$ yatak yüksekliğindeki AP içerisindeki kirleticinin adsorplanacağı mevcut aktif alanların fazla olması sebebiyle daha düşük $\mathrm{C}_{\mathrm{e}} / \mathrm{C}_{0}$ verileri elde edilmiştir.

Smaranda ve arkadaşları [28] 2017 yllında toprak örnekleri ile adsorpsiyon kolon çalışmasında $20 \mathrm{~cm}$ yatak yüksekliğinde en yüksek giderim verimi elde etmişlerdir. Hodaifa ve diğerleri [29] ise kolon yüksekliğini $4.4 \mathrm{~cm}$ olarak sabitlemişlerdir. Nguyen ve arkadaşları [30] ağır metal gideriminde $12 \mathrm{~cm}$ kolon yüksekliğinde çalışmışlardır. Literatür çalışmasında, kullanılan yatak yüksekliği karşılaştırıldığında farklı yatak yüksekliklerinde çalışmalar mevcuttur. Bunun sebebi ise atıksu özelliği, adsorban türü ve işletme koşulları olarak sayılabilir.

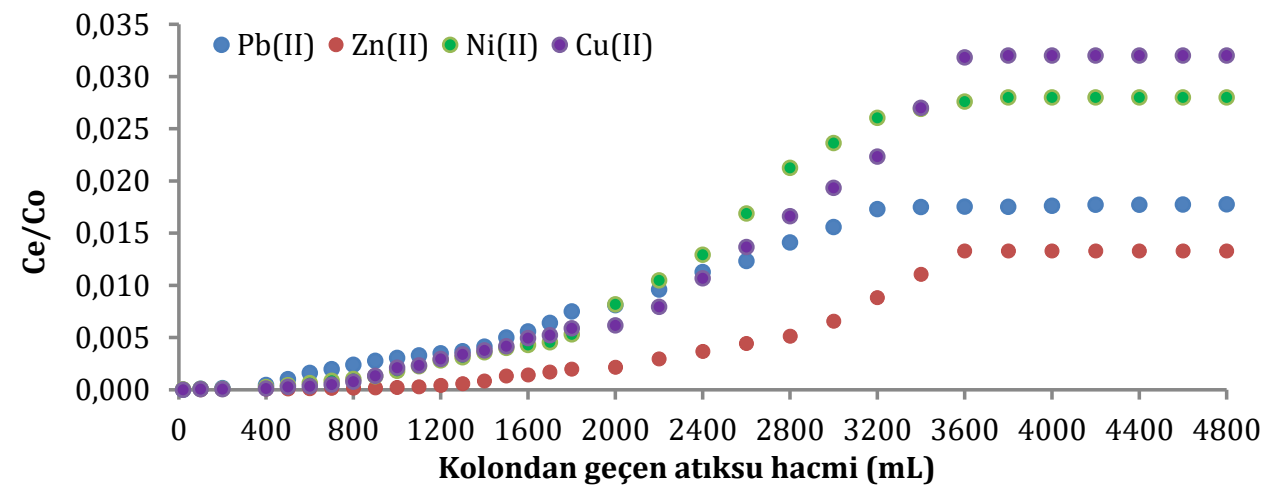

Şekil 3. AP kolonunda $15 \mathrm{~cm}$ yatak yüksekliğindeki kolon kırılma eğrisi (Akış hızı=20 mL/dk)

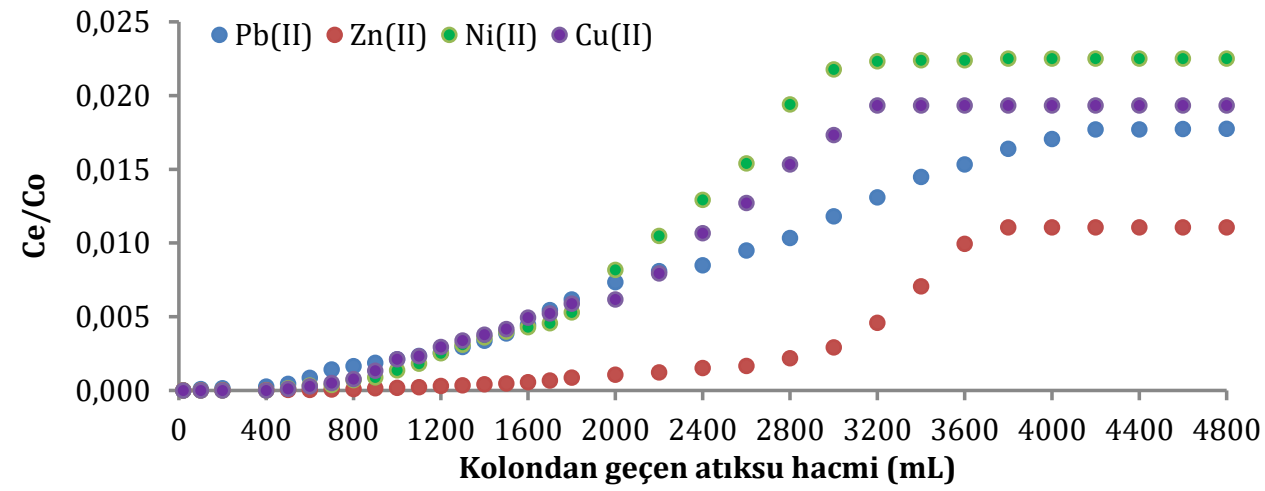

Şekil 4. AP kolonunda $25 \mathrm{~cm}$ yatak yüksekliğindeki kolon kırılma eğrisi (Akış hızı=20 mL/dk) 


\subsection{Akış hızının etkisi}

AP kullanılan sabit yataklı kolonda $\mathrm{Pb}(\mathrm{II})$, $\mathrm{Zn}(\mathrm{II}), \quad \mathrm{Ni}(\mathrm{II})$ ve $\mathrm{Cu}(\mathrm{II})$ iyonlarının adsorpsiyonu üzerine akış hızının etkisi; Tablo 2'de verilen ağır metal konsantrasyonundaki akü geri dönüşüm tesisi atıksuyunun $25^{\circ} \mathrm{C}$ sicaklıkta, $25 \mathrm{~cm}$ kolon yüksekliğinde; 20 ve $30 \mathrm{~mL} / \mathrm{dk}$ akış hızlarında kolondan geçirilmesiyle elde edilmiştir. Sonuçlar Şekil 4 ve Şekil 5'te görülmektedir.

Adsorpsiyonda rol oynayan yığın akış, difüzyon ve yüzeye tutunma gibi taşınım mekanizmaları dikkate alındığında; adsorban ile giderimi amaçlanan kirleticinin temas süresinin uzaması transferi hızlandırmaktadır. Yapılan ön çalışmalarda $40 \mathrm{~mL} / \mathrm{dk}$ akış hızında istenilen kolon servis sürelerine ulaşılamaması sebebiyle çalıșmaya dahil edilmemiștir. $25 \mathrm{~cm}$ kolon yüksekliğinde $30 \mathrm{~mL} / \mathrm{dk}^{\prime} \mathrm{da}$ yapılan çalışmada ise 20 $\mathrm{mL} / \mathrm{dk}$ akış hızından daha yüksek adsorplanma verimleri elde edilmiştir.

Hodaifa ve arkadaşları [29] adsorpsiyon kolon çalışmasında zeytin çekirdeği ile sulardan demir giderimini araştırmışlardır. Akış hızını $3.3 \mathrm{~mL} / \mathrm{dk}$ olarak ayarladıklarında yüksek giderim verimleri elde etmişlerdir. Johari ve arkadaşları [31], adsorpsiyon kolonunda Hindistan cevizi kabuğu ile civa giderimini araştırmışlardır. Kolondaki optimum akış hızını $50 \mathrm{~mL} / \mathrm{dk}$ olarak belirlemişler ve $\% 80$ ve üzerinde giderim verimlerine ulașmıșlardır. Martín-Lara ve diğerleri [32], zeytin çekirdeği ile ağır metal içeren gerçek atıksu arıtımında kolondaki akış hızını $4 \mathrm{~mL} / \mathrm{dk}$ olarak belirlemişlerdir. Brion-Roby ve arkadaşları [7] ise $0.5-2 \mathrm{~mL} / \mathrm{dk}$ aralığında akış hızı ile yüksek giderim verimleri elde etmişlerdir.

Literatürdeki farklı çalışmalar incelendiğinde, bu çalışmada elde ettiğgimiz sonuçlar ile uyumlu olduğu görülmektedir. Buna ek olarak çalışmamızda daha yüksek akış hızı ile yüksek giderim verimlerinin sağlanmış olması kısa sürede daha fazla atıksuyun arıtılabileceği anlamı taşıdığından adsorpsiyon sürecini kolaylaştırmaktadır.

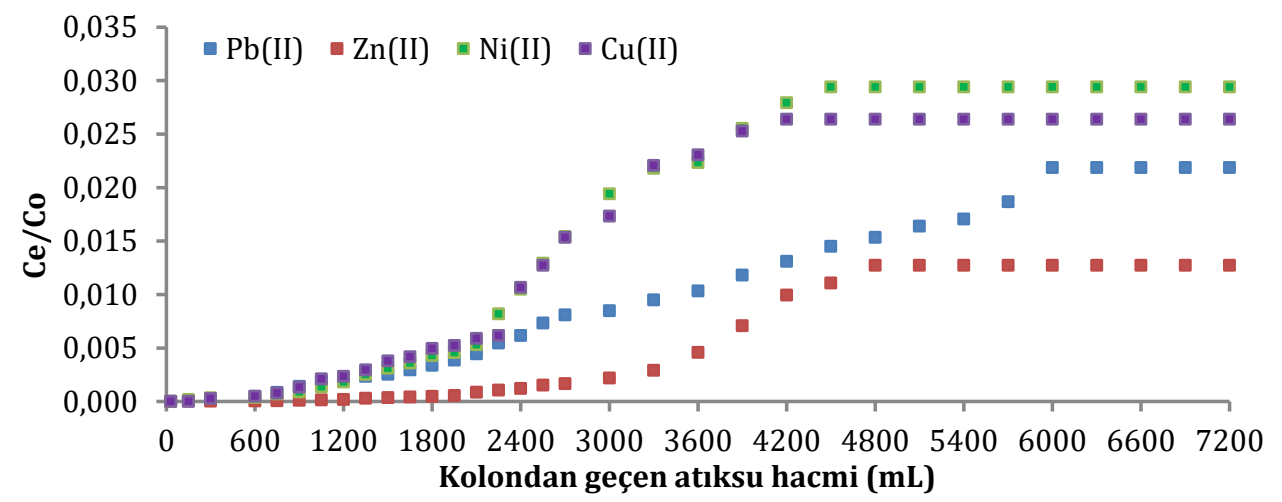

Şekil 5. AP kolonunda $30 \mathrm{~mL} / \mathrm{dk}$ akış hızındaki kolon kırılma eğrisi (Yatak yüksekliği=25 cm)

\subsection{SEM analizi}

Çalışmada, adsorban olarak kullanılan AP'nin ağır metaller ile etkileșimi sonucunda arıtma veriminin doğruluğunu desteklemek için SEM görüntüleri alınmıştır. Kullanılan adsorbanın 
adsorpsiyon işlemi öncesi ve sonrası SEM görüntüleri Şekil 7 ve Şekil 8'de verilmiştir.

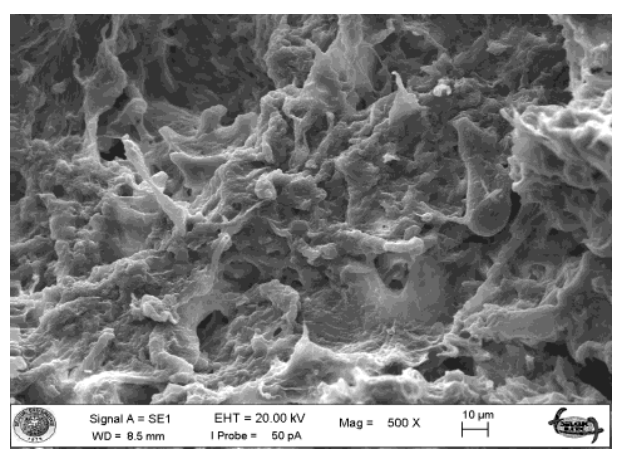

Şekil 7. Adsorpsiyon öncesi AP görüntüsü

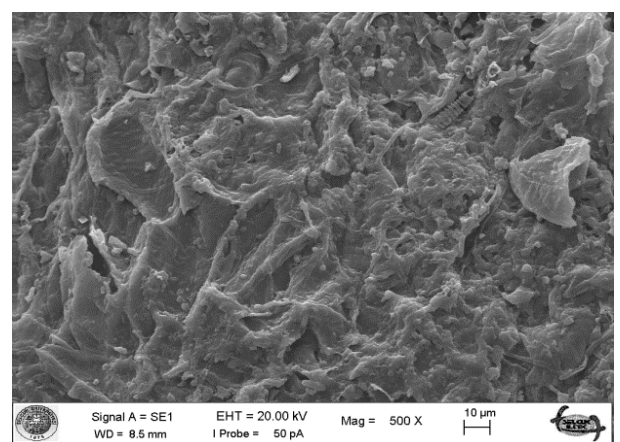

Şekil 8. Adsorpsiyon sonrası AP görüntüsü

Yapılan SEM analizi sonucunda, AP'nin adsorpsiyon sonrasında aktif alanlarına akü geri dönüşüm tesisi atıksuyundaki ağır metallerin bağlanarak gideriminin sağlandığı, Şekil 7 ve Şekil 8 karşılaştırıldığında açıkça görülmektedir.

\subsection{FTIR analizi}

Kolon sisteminde kullanılan AP'nin adsorpsiyon öncesi ve sonrası FTIR spektrumları Şekil 9'da verilmiştir.

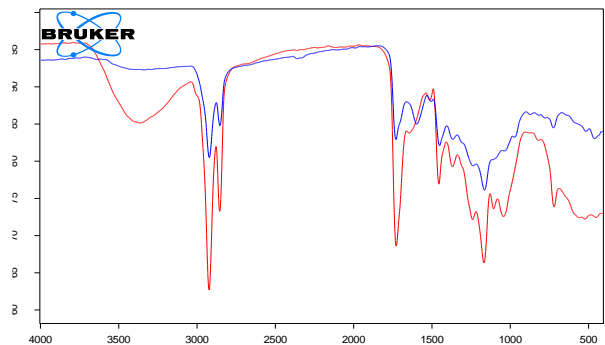

Şekil 9. AP’nin adsorpsiyon öncesi ve sonrası FTIR spekturumları

Şekil 9'da verilen FTIR spektrumlarında akü sanayisi atıksuyundaki ağır metallerin AP üzerine adsorpsiyonun gerçekleştiği görülmektedir. $2923 \mathrm{~cm}^{-1} \mathrm{ve}$ $2853 \mathrm{~cm}^{-1}$ dalga boyundaki pikler alifatik yapının var olduğunu kanıtlamaktadır. $1705 \mathrm{~cm}^{-1}$ dalga boyundaki bağ başlangıç katranda var olan lineer alifatik aldehitler, ketonlar ve karboksillerdeki CO'nun uzatılmasıyla ilişkili olduğunu göstermektedir. $1460 \mathrm{~cm}^{-1}$ dalga boyunda aromatik hidrokarbon pikleri oluşurken, $1100 \mathrm{~cm}^{-1}$ ve $1300 \mathrm{~cm}^{-1}$ arasindaki dalga boylarında C-O bağları olușmaktadır. Ayrıca, $1030 \mathrm{~cm}^{-1}$ dalga boyundaki pikler C-C ve C-O'nun genişletilmiş şekilleriyle açıklanmaktadır.

\section{Tartışma ve Sonuç}

$\mathrm{Bu}$ çalışmada akü geri dönüşüm tesisi atıksuyundaki ağır metaller, doğal organik atık olan pirina kullanılarak adsorpsiyon kolonu ile giderimi araştırılmıştır. Çalışmalar gerçek atıksu ile yapıldığından, kirletici konsantrasyonu ve $\mathrm{pH}$ gibi parametrelerde değişiklik yapılmamış olup; kolon kırılma eğrisine kolon yüksekliğinin ve akış hızının etkisi araştırılmıştır. Kolon içerisinde aktifleştirme işlemi tabii tutulan pirina kullanılmıştır.

Kolonda kullanılan adsorbanın miktarının 45 g'dan 75 g'a artmasiyla adsorpsiyon veriminin arttığı tespit edilmiştir. Mevcut ağır metaller için \%95 ve üzerinde giderim verimi, $15 \mathrm{~cm} \mathrm{(45} \mathrm{g)} \mathrm{kolon}$ yüksekliğinde $\mathrm{Cu}(\mathrm{II}), \mathrm{Zn}(\mathrm{II}), \mathrm{Ni}(\mathrm{II})$ ve 
$\mathrm{Pb}(\mathrm{II})$ için sırasıyla; 2000, 2800, 1800 ve $1600 \mathrm{~mL}$; kolon yüksekliği 25 cm'ye (75 g) artırıldığında ise $\mathrm{Cu}(\mathrm{II}), \mathrm{Zn}(\mathrm{II}), \mathrm{Ni}(\mathrm{II})$ ve $\mathrm{Pb}(\mathrm{II})$ için sırasıyla; 1600, 3200, 1600 ve 1400 mL'de kolon kırılma noktaları tespit edilmiştir. Bu karşılaştırma sonucu akü geri dönüşüm tesisi atıksuyundaki yüksek konsantrasyondaki Zn(II) iyonlarının AP'nin aktif yüzeylerini daha hızlı doldurduğundan, kolon kırılma noktası en yüksek hacimde gerçekleşmektedir. Diğer ağır metallerin ise kolon kırılma noktaları düşük olmasına rağmen yüksek giderim verimleriyle kolondan çıktıkları tespit edilmiştir.

Ayrıca 20 ve $30 \mathrm{~mL} / \mathrm{dk}$ akış hızlarından $30 \mathrm{~mL} / \mathrm{dk}^{\prime} \mathrm{da}$ daha fazla giderim verimi elde edilmiştir. Gerçek ölçekli kolon çalışmalarında deşarj limit değerlerinin karşılanması için bu giderim verimleri doğrultusunda seri bağlı kolon sistemine geçilebilir.

Su Kirliliği Kontrolü Yönetmeliği (SKKY)'nde Tablo 25'e göre deşarj standartları ve akü geri dönüşüm atıksuyu için bu çalışmada elde edilen giderim verimleri Tablo 3'te verilmiştir.

Tablo 3. Adsorpsiyon kolon sonuçları.

\begin{tabular}{cccc}
\hline $\begin{array}{c}\text { Ağır } \\
\text { Metal }\end{array}$ & $\begin{array}{c}\text { Çıkıș } \\
\text { Kons. } \\
(\mathrm{mg} / \mathrm{L})\end{array}$ & $\begin{array}{c}\text { Giderim } \\
\text { Verimi } \\
(\%)\end{array}$ & $\begin{array}{c}\text { Sınır } \\
\text { Değeri } \\
(\mathrm{mg} / \mathrm{L})^{*}\end{array}$ \\
\hline $\mathrm{Pb}(\mathrm{II})$ & 0.12 & 98 & 3 \\
$\mathrm{Zn}(\mathrm{II})$ & 0.57 & 99 & 10 \\
$\mathrm{Ni}(\mathrm{II})$ & 0.08 & 97 & 5 \\
$\mathrm{Cu}(\mathrm{II})$ & 0.05 & 97 & 2 \\
\hline
\end{tabular}

*SKKY, 2004 [33].

Tablo 3'te görüldüğü gibi $\mathrm{Pb}(\mathrm{II}), \mathrm{Zn}(\mathrm{II})$, $\mathrm{Ni}(\mathrm{II})$ ve $\mathrm{Cu}(\mathrm{II})$ için $\% 97$ ve üzerinde elde edilen giderim verimleri ile SKKY'deki Tablo 25 için deşarj sınır değerleri sağlanmaktadır. Atıksu içerisindeki Cu(II) miktarı deşarj standartları altında kalmaktadır ancak arıtım sistemiyle miktarı daha da düşürülmüştür.

Kolon yatağı olarak kullanılan AP'nin rejenerasyon çalışmasında $30 \mathrm{~mL} / \mathrm{dk}$ akış hızında akü geri dönüşüm atıksuyu içerisindeki ağır metallerin giderim verimleri takip edilmiştir. Atıksu içerisindeki ağır metallerin miktarlarının ve deşarj sınır değerlerinin farklı olması sebebiyle; $\mathrm{Pb}(\mathrm{II}), \mathrm{Zn}(\mathrm{II}), \mathrm{Ni}(\mathrm{II})$ ve $\mathrm{Cu}(\mathrm{II})$ için ortak bir süre belirlenmiştir. Çıkış konsantrasyonlarının sınır değerlerin altında kalması ve giderim verimlerinin \%95 ve üzerinde olması açısından, kolon yatak malzemesine sürekli sistemde 2 saat sonunda rejenerasyon yapılması uygun görülmüştür.

Adsorban olarak kullanılan AP ile akü geri dönüşüm tesisi atıksuyundaki ağır metallerin gideriminde ise kolon kırılma noktasındaki adsorpsiyon kapasitesi 2.64 mg/g olarak hesaplanmıştır. Bulunan bu sonuç literatürle karşılaştırıldığında çok çeşitli adsorplama kapasitelerinin rapor edildiği görülmektedir. $\mathrm{Bu}$ durum kullanılan düşük maliyetli doğal adsorbanın cinsine, giderimi amaçlanan ağır metalin iyonu çeşidine ve adsorpsiyona etki eden diğer parametrelere göre farklılık gösterdiği düşünülmektedir.

Yapılan bu çalışma sonucunda zeytinyağ üretiminin atığ aktifleștirilmesiyle, akü geri dönüșüm tesisi atıksuyundaki ağır metallerin gideriminde adsorban olarak kullanılabileceğini göstermektedir.

\section{Teşekkür}

Bu çalışma, Aksaray Üniversitesi Bilimsel Araştırma Projeleri (BAP) Koordinatörlüğü tarafından 2015-026 nolu proje ile desteklenmiştir.

\section{Kaynakça}

[1] Gök, O., Çimen Mesutoğlu, Ö. 2017. Ağır Metallerin Giderimi için Düşük Maliyetli Adsorban Olarak Pirina Kullanimı, Journal of the Faculty of Engineering and Architecture of Gazi 
University, Cilt. 32:2, s. 507-516. DOI: $10.17341 /$ gazimmfd.322176.

[2] Xu, J., Coa, Z., Zhang, Y., Yuan, Z., Lou, Z., Xu, X., Wang, X. 2018. A review of functionalized carbon nanotubes and graphene for heavy metal adsorption from water: Preparation, application, and mechanism, Chemosphere, Cilt, 195, s. 351-364.

[3] Hernández-Hernández, L.E., BonillaPetriciolet, A., Mendoza-Castillo, D.I., Reynel-Ávila, H.E. 2017. Antagonistic binary adsorption of heavy metals using stratified bone char columns, Journal of Molecular Liquids, Cilt, 241, s. 334-346.

[4] Dissanayake, D.M.R.E.A., Wijesinghe, W.M.K.E.H., Iqbal, S.S., Priyantha, N., Iqbal, M.C.M. 2016. Isotherm and kinetic study on $\mathrm{Ni}(\mathrm{II})$ and $\mathrm{Pb}(\mathrm{II})$ biosorption by the fern Asplenium nidus L., Ecological Engineering, Cilt. 88, S. 237-241. DOI: 10.1016/j.ecoleng.2015.12.028.

[5] Sherlala, A.I.A., Raman, A.A.A., Bello, M.M., Asghar, A. 2018. A review of the applications of organofunctionalized magnetic graphene oxide nanocomposites for heavy metal adsorption, Chemosphere, Cilt, 193, s. 1004-1007.

[6] Oancea, P., Meltzer, V. 2013. PhotoFenton process for the degradation of tartrazine (E102) in aqueous medium, Journal of the Taiwan Institute of Chemical Engineers, Cilt, 44, s. 990-994.

[7] Brion-Robya, R., Gagnona, J., Deschênes, J.S., Chabot, B. 2018. Investigation of fixed bed adsorption column operation parameters using a chitosan material for treatment of arsenate contaminated water, Journal of Environmental Chemical Engineering, Cilt, 6, s. 505-511.

[8] Ali, R.M., Hamad, H.A., Hussein, M.M., Malash, G.F. 2016. Potential of using green adsorbent of heavy metal removal from aqueous solu- tions: adsorption kinetics, isotherm, thermodynamic, mechanism and economic analysis, Ecological Engineering, Cilt, 91, s. 317-332.

[9] İrdemez, Ş., Ekmekyapar Torun, F., Durmuş, G. 2017. Montmorillonit Mineral Kayacı Kullanılarak Atıksulardan Krom (III) İyonlarının Giderimi ve Etki Eden Parametrelerin İncelenmesi, Dokuz Eylül Üniversitesi-Mühendislik Fakültesi Fen ve Mühendislik Dergisi, Cilt. 19:57, s. 701-711.

[10] Callery, O., Healy, M.G., Rognard, F., Barthelemy, L., Brennan, R.B. 2016. Evaluating the long-term performance of low-cost adsorbents using small-scale adsorption column experiments, Water Research, Cilt, 101, s. 429-440.

[11] Özdemir, Ö., Turan, M. 2013. Sabit yatakl modifiye zeolit kolon reaktörde tekstil atıksuyundan renk giderimi ve zeolit yatağının rejenerasyonu, İTÜ Dergisi/e : Su Kirlenmesi ve Kontrolü, Cilt, 17:3, s. 35-44.

[12] Vukelic, D., Boskovic, N., Aparski, B., Radonic, J., Budak, I., Pap, S., Sekulic, M.T. 2018. Eco-design of a low-cost adsorbent produced from waste cherry kernels, Journal of Cleaner Production, Cilt, 174, 1620-1628.

[13] Saini, S., Arora, S., Kirandeep, Singh, B.P., Katnoria, J.K., Kaur, I. 2018. Nitrilotriacetic acid modified bamboo charcoal (NTA-MBC): An effective adsorbent for the removal of $\mathrm{Cr}$ (III) and $\mathrm{Cr}$ (VI) from aqueous solution, Journal of Environmental Chemical Engineering, Cilt, 6, s. 2965-2974.

[14] Çelebi, H., Gök, O. 2017. Evaluation of Lead Adsorption Kinetics and Isotherms from Aqueous Solution Using Natural Walnut Shell, International Journal of Environmental Research, Cilt, 11:1, s. 83-90.

[15] Wu, Y., Fan, Y., Zhang, M., Ming, Z., 
Yang, S., Arkin, A., Fang, F. 2016 Functionalized agricultural biomass as a low-cost adsorbent: Utilization of rice straw incorporated with amine groups for the adsorption of $\mathrm{Cr}(\mathrm{VI})$ and $\mathrm{Ni}(\mathrm{II})$ from single and binary systems, Biochemical Engineering Journal, Cilt, 105, s. 2735.

[16] Shahmohammadi-Kalalagh, S. Babazadeh, H., Nazemi, A.H., Manshouri, M. 2011. Isotherm and kinetic studies on adsorption of $\mathrm{Pb}$, $\mathrm{Zn}$ and $\mathrm{Cu}$ by kaolinite, Caspian Journal of Environmental Science, Cilt, 9, s. 243-255.

[17] Vieira, M.G.A., Almeida, N.A.F., deGimenes, M.L., Silva, M.G.C. 2010. Sorption kinetics and equilibrium for the removal of nickel ions from aqueous phase on calcined Bofe bentonite clay, Journal of Hazardous Materials, Cilt, 177, s. 362-371.

[18] Abbasi Z., Alikarami M., Nezhad E.R., Moradi F., Moradi V. 2013. Adsorptive Removal of $\mathrm{Co} 2+$ and $\mathrm{Ni2}+$ by Peels of Banana from Aqueous Solution. Universal Journal of Chemistry, Cilt, 1, s. 90-95.

[19] Cataldo, S., Gianguzza, A., Milea, D., Muratore, N., Pettignano, A., Sammartano, S. 2018. A critical approach to the toxic metal ion removal by hazelnut and almond shells, Environmental Science and Pollution Research, Cilt, 25, s. 42384253.

[20] Banerjee, M., Basu, R.K., Das, K.S. 2018. $\mathrm{Cu}(\mathrm{II})$ removal using green adsorbents: kinetic modeling and plant scale-up design, Environmental Science and Pollution Research,

[21] Doymaz, I., Gorel, O., Akgün, N.A. 2004. Drying characteristics of the solid by product of olive oil extraction, Biosystem Engineering, Cilt. 88, s. 213-219.
[22] Çimen, Ö. 2014. Pirina kullanılarak sulu çözeltilerden adsorpsiyon yöntemiyle ağır metallerin giderimi, Aksaray Üniversitesi, Fen Bilimleri Enstitüsü, Yüksek Lisans Tezi, 104s, Aksaray.

[23] Arshadi, M., Amiri, M.J., Mousavi, S. 2014. Kinetic, equilibrium and thermodynamic investigations of $\mathrm{Ni}(\mathrm{II}), \mathrm{Cd}(\mathrm{II}), \mathrm{Cu}(\mathrm{II})$ and $\mathrm{Co}(\mathrm{II})$ adsorption on barley straw ash, Water Resources and Industry, Cilt, 6, s. 1-17.

[24] Koçer, 0. 2013. Zeytin posası (pirina) üzerine malaşit yeşili'nin sulu çözeltiden adsorpsiyonu, Kilis 7 Aralık Üniversitesi, Fen Bilimleri Enstitüsü, Yüksek Lisans Tezi, 53s, Kilis.

[25] Kumar, U., Bandyopadhyay, M. 2006. Sorption of cadmium from aqueous solution using pretreated rice husk, Bioresource Technology, Cilt, 97:1, s. 104-109.

[26] Orhan, R., Erdem, M. 2017. Üzüm sapından hazırlanan aktif karbon ile sulu çözeltilerden Ni(II)'nin giderimi, Frrat Üniversitesi Mühendislik Bilimleri Dergisi, Cilt, 29:1, s. 319-324.

[27] Cutillas-Barreiro, L., Paradelo, R., Igrexas-Soto, A., Núñez-Delgado, A., Fernández-Sanjurjo, M.J., ÁlvarezRodriguez, E., Garrote, G., NóvoaMuñoz,J.C., Arias-Estévez, M. 2016. Valorization of biosorbent obtained from a forestry waste: Competitive adsorption, desorption and transport of $\mathrm{Cd}, \mathrm{Cu}, \mathrm{Ni}, \mathrm{Pb}$ and $\mathrm{Zn}$, Ecotoxicology and Environmental Safety, Cilt, 131, s. 118-126.

[28] Smaranda, C., Popescu, M.C., Bulgariu, D., Malut, T., Gavrilescu, M. 2017. Adsorption of organic pollutants onto a Romanian soil: Column dynamics and transport, Process Safety and Environmental Protection, Cilt, 108, s. 108-120.

[29] Hodaifa, G., Alami, S.B.D., OchandoPulido, J.M., Víctor-Ortega, M.D. 
2014. Iron removal from liquid effluents by olive stones on adsorption column: breakthrough curves, Ecological Engineering, Cilt, 73 , s. 270-275.

[30] Nguyen, T.C., Loganathan, P., Nguyen, T.V., Vigneswaran, S., Kandasamy, J., Naidu, R. 2015. Simultaneous adsorption of $\mathrm{Cd}, \mathrm{Cr}$, $\mathrm{Cu}, \mathrm{Pb}$, and $\mathrm{Zn}$ by an iron-coated Australian zeolite in batch and fixedbed column studies, Chemical Engineering Journal, Cilt, 270, s. 393404.

[31] Johari, K., Saman, N., Song, S.T., Chin, C.S., Kong, H., Mat, H. 2016. Adsorption enhancement of elemental mercury by various surface modified coconut husk as eco-friendly low-cost adsorbents, International Biodeterioration \& Biodegradation, Cilt, 109, s. 45-52.

[32] Martín-Lara, M.A., Blazquez, G., Trujillo, M.C., Perez, A., Calero, M. 2014. New treatment of real electroplating wastewater containing heavy metal ions by adsorption onto olive stone, Journal of Cleaner Production, Cilt, 81, S. 120-129.

[33] SKKY, 2004. Su Kirliliği Kontrolü Yönetmeliği Tabloları. http://www.resmigazete.gov.tr/esk iler/2004/12/Su\%20Kirliliği \%20ek leri.htm

(Erişim Tarihi: 19.07.2017) 